\title{
Stat3 as a molecular target in RNA interference-based treatment of oral squamous cell carcinoma
}

\author{
SEBASTIAN KRYSTIAN KLOSEK, KOH-ICHI NAKASHIRO, SHINGO HARA, \\ HIROYUKI GODA and HIROYUKI HAMAKAWA \\ Department of Oral and Maxillofacial Surgery, Ehime University Graduate \\ School of Medicine, Shitsukawa 454, Toon, Ehime 791-0295, Japan
}

Received May 29, 2008; Accepted July 24, 2008

DOI: 10.3892/or_00000085

\begin{abstract}
Constitutive activation of signal transducer and activator of transcription 3 (Stat3) has been observed in many human malignancies. Using the sequence-specific RNA interference (RNAi) method to switch off Stat3 expression, it may be possible to arrest cancer growth. In this study, we aimed to identify the most effective sequence of a synthetic small interfering RNA (siRNA) specific for Stat3 (Stat3siRNA) and the effect of Stat3 suppression on the growth of oral squamous cell carcinoma cells. Ten designed siRNAs with known sequences were screened for the best RNAi effect at the working concentrations of 1 and $10 \mathrm{nM}$. The range of reduction of Stat 3 expression varied from 21 to $67 \%$ for $10 \mathrm{nM}$ siRNAs, and from 13 to $73 \%$ for $1 \mathrm{nM}$ siRNAs. Three out of the 10 screened siRNAs reduced Stat 3 expression to lower levels compared with the GFP-siRNA control. The interferon response of some siRNAs was observed at a concentration of $10 \mathrm{nM}$. However, at $1 \mathrm{nM}$, the mRNA levels of interferon response genes (OAS1, OAS2, MX1 and ISFG $3 \gamma$ ) remained unchanged. The growth of GFP-SAS, HSC-3, HSC-4 and KB cells was strongly inhibited by the use of three effective Stat3-siRNAs in comparison with other Stat3-siRNAs and GFP-siRNA. Moreover, the mRNA levels of genes for which transcription is activated by Stat 3 were markedly suppressed. These results suggest that targeting Stat3 using siRNA may constitute a useful approach for the treatment of oral squamous cell carcinoma.
\end{abstract}

\section{Introduction}

Signal transducer and activator of transcription 3 (Stat3) is a key molecule for many biological processes such as embryonic

Correspondence to: Dr Koh-ichi Nakashiro, Department of Oral and Maxillofacial Surgery, Ehime University Graduate School of Medicine, Shitsukawa 454, Toon, Ehime 791-0295, Japan

E-mail: nakako@m.ehime-u.ac.jp

Key words: signal transducer and activator of transcription 3, synthetic small interfering RNA, interferon response, oral squamous cell carcinoma development, organogenesis, innate and adaptive immune responses, regulation of cell differentiation and cell cycle progression, and apoptosis $(1,2)$. However, a significant number of studies have suggested that phosphorylated Stat3 protein is involved in promoting tumorigenesis. Moreover, a constitutively active mutant of Stat 3 has been demonstrated to transform fibroblasts and induce tumour formation in nude mice (3). Constitutive activation of Stat3 signalling has been reported in many human cancer types $(1,4-9)$. In our previous research, $74 \%$ of oral squamous cell carcinoma (OSCC) tissues examined immunohistochemically exhibited a markedly elevated phosphorylation of Stat3 (10). Persistent signalling of Stat 3 has been demonstrated to contribute to oncogenesis by stimulating cell proliferation and preventing apoptosis by the up-regulation of genes encoding cell cycle regulators, survivin and apoptosis inhibitors (11-17).

Stat3 itself serves as a molecular target in cancer therapy. The blockade of Stat protein signalling can be achieved by various means, including dominant-negative mutants, antisense methods $(18,19)$, inhibition of upstream signalling $(20)$, phosphotyrosyl peptides (21) and the double-stranded DNA (dsDNA) decoy method (22). A further strategy for abrogating protein expression in human cells is based on destroying mRNA by RNA interference (RNAi) (23), using either small hairpin RNA (shRNA) (24) or small interfering RNA (siRNA) (15).

In the current study, we examined the influence of siRNAs specific for the Stat3 sequence on the expression of Stat 3 and followed its effects in OSCC cells. The aim was to identify the most effective sequence of Stat3-siRNA in order to obtain a powerful tool for targeting Stat3 expression in RNAi-based human cancer treatment.

\section{Materials and methods}

Cells and cell culture. We used human OSCC cell lines (HSC-2, HSC-3, HSC-4, KB, Ca9-22, GFP-SAS, Scc9, Scc25, Scc66 and Scc11) and a human epidermal keratinocyte cell line (HaCaT). GFP-SAS cells were generated by transfecting SAS cells with a gene encoding green fluorescent protein (GFP). The cells were maintained in Dulbecco's modified Eagle's medium (DMEM; Invitrogen, Carlsbad, CA) containing $10 \%$ fetal bovine serum (FBS; Biosource International, Camarillo, CA), $100 \mathrm{U} / \mathrm{ml}$ penicillin, and $100 \mu \mathrm{g} / \mathrm{ml}$ strepto- 
mycin (Invitrogen) (referred to as complete medium), and incubated in a humidified atmosphere of $95 \%$ air and 5\% $\mathrm{CO}_{2}$ at $37^{\circ} \mathrm{C}$. For evaluation of the constitutive activation of Stat 3 in these cells, the growth medium was replaced with a plain one.

Synthetic small interfering RNAs (siRNAs). Cells were transfected with small interfering RNAs specific for Stat3 (Stat3-siRNA: Smartpool ${ }^{\circledR}$ siRNA reagents, Cat. No. M003544-00-05; Dharmacon, Lafayette, CO) as well as with 10 designed Stat3-siRNAs (B-Bridge International, Inc., Mountain View, CA), and green fluorescent protein (GFPsiRNA: Smartpool siRNA reagents, Cat. No. D-001300-01-20) as a control at working concentrations of 1 and $10 \mathrm{nM}$ using lipofection (Lipofectamine ${ }^{\mathrm{TM}}$ 2000; Invitrogen) according to the manufacturer's instructions. After a 72 h gene knockdown, the cells were recovered by treatment with $0.05 \%$ trypsin$0.53 \mathrm{mM}$ EDTA (Invitrogen) and used for RNA isolation and cell growth assays. The target sequences of 10 Stat3siRNAs were: 5'-CUU GGA UUG AGA GUC AAG A-3' (no. 1), 5'-GAG AUU GAC CAG CAG UAU A-3' (no. 2), 5'-GUU UCU UCA GAG CAG GUA U-3' (no. 3), 5'-GUA GAG AAU CUC CAG GAU G-3' (no. 4), 5'-GGA GAA GCA UCG UGA GUG A-3' (no. 5), 5'-CCU AGA UCG GCU AGA AAA C-3' (no. 6), 5'-UCC AGU UCA CUA CUA AAG U-3' (no. 7), 5'-GCA GAA UUC AAA CAC UUG A-3' (no. 8), 5'-GGA GCA GAG AUG UGG GAA U-3' (no. 9) and 5'-CCA ACG ACC UGC AGC AAU A-3' (no. 10).

Cell growth assay. Synthetic siRNA-transfected cells were seeded in complete medium in flat-bottomed 6-well plates (Falcon; BD Biosciences, San Jose, CA) at a density of $5 \times 10^{4}$ cells per well. The cells were recovered by treatment with $0.05 \%$ trypsin-0.53 mM EDTA and counted using a Z1 Coulter counter (Beckman Coulter, Fullerton, CA).

Western blot analysis. Cells grown in monolayers were harvested at subconfluency and lysed with CelLytic M cell lysis reagent (Sigma-Aldrich, St. Louis, MO) containing a protease inhibitor cocktail tablet (Roche Diagnostics, Mannheim, Germany) and phosphatase inhibitor cocktails I and II (Sigma-Aldrich). The samples were centrifuged at $12,000 \mathrm{x} \mathrm{g}$ for $10 \mathrm{~min}$ at $4^{\circ} \mathrm{C}$. Samples of the resulting protein supernatant were electrophoresed on sodium dodecyl sulfate (SDS)-polyacrylamide gels (Bio-Rad, Hercules, CA) and transferred to polyvinylidene difluoride membranes (Millipore, Bedford, MA). The membranes were blocked with 5\% non-fat dry milk (Wako, Osaka, Japan) in 1X T-TBS [25 mM Tris$\mathrm{HCl}, 125 \mathrm{mM} \mathrm{NaCl}$ and $0.1 \%$ Tween-20 (Sigma)] overnight at $4{ }^{\circ} \mathrm{C}$, probed with primary antibodies overnight at $4^{\circ} \mathrm{C}$ and then with horseradish peroxidase-conjugated secondary antibodies for $1 \mathrm{~h}$. The immune complexes were visualized using an enhanced chemiluminescence (ECL) Plus or ECL advance kit (Amersham Biosciences, Piscataway, NJ) according to the manufacturer's protocol. For the internal control, the blots were stripped with $62.5 \mathrm{mM}$ Tris- $\mathrm{HCl}(\mathrm{pH} 6.8)$ buffer containing $0.7 \%$ 2-mercaptoethanol and $2 \%$ SDS (Sigma) at $50^{\circ} \mathrm{C}$ for $30 \mathrm{~min}$ and reprobed with mouse anti- $\beta$-tubulin monoclonal antibody (BD Biosciences). The primary antibodies used were polyclonal antibodies against Stat 3 and
phospho-Stat3 (Tyr705) (Cell Signaling Technology, Inc., Beverly, MA), and we used secondary antibodies against mouse or rabbit IgG (Amersham Biosciences).

RNA isolation and real-time quantitative RT-PCR. Total RNA was extracted using the RNA isolation solution, Isogen (Nippon Gene, Toyama, Japan), according to the manufacturer's instructions. Reverse transcriptase-polymerase chain reaction (RT-PCR) amplification was performed using a QuantiTect ${ }^{\mathrm{TM}}$ Probe RT-PCR Kit (Qiagen GmbH, Hilden, Germany). The LightCycler cycling conditions were set as: reverse transcription at $55^{\circ} \mathrm{C}$ for $10 \mathrm{~min}$, initial denaturation at $95^{\circ} \mathrm{C}$ for $30 \mathrm{sec}$ followed by 55 cycles at $95^{\circ} \mathrm{C}$ for $1 \mathrm{sec}$, $60^{\circ} \mathrm{C}$ for $15 \mathrm{sec}$ and $72^{\circ} \mathrm{C}$ for $13 \mathrm{sec}$. Specific cDNAs, along with porphobilinogen deaminase (PBGD) cDNA as an internal control, were amplified separately using an oligonucleotide probe labelled with a 5'-fluorescent reporter and a 3'-quencher dye. The 5'-fluorescent reporter dye was cleaved from the cDNA by the 5'-nuclease activity of Taq DNA polymerase and its fluorescence was detected with LightCycler (Roche Diagnostics). Automated calculations were performed by the second derivative maximum method (LC software, version 3.5). The relative mRNA levels were measured using the comparative CT method ( $\Delta \Delta \mathrm{CT}$ method). Taq Man gene expression assays for Stat3, PBGD, 2',5'-oligoadenylate synthetases 1 and 2 (OAS1 and 2), interferon-induced myxovirus-resistance protein 1 (MX1), interferon-stimulated gene factor $3 \gamma$ (ISGF3 $\gamma$ ), cyclin D1 (CCND1), vascular endothelial growth factor (VEGF) and matrix metalloprotease-10 (MMP-10) were all purchased from Applied Biosystems (Foster City, CA).

\section{Results}

Constitutive activation of Stat3 in human OSCC cell lines. In order to determine whether Stat 3 is constitutively activated in OSCC cell lines, we first examined its expression and the phosphorylation of tyrosine 705 by Western blot analysis. Various levels of Stat 3 phosphorylation were found in the OSCC cells in the absence of FBS. However, the GFP-SAS, HSC-4, HSC-3 and KB cell lines exhibited relatively high Stat3 activation (Fig. 1).

Knockdown of Stat3 expression in GFP-SAS cells by Smartpool Stat3-siRNA. The high transfection efficiency and the RNAi effect of GFP-expressing SAS cells were previously demonstrated in our laboratory (data not shown). These cells were subjected to knockdown experiments with Smartpool Stat3-siRNA at the working concentration of $10 \mathrm{nM}$. Transfection of GFP-SAS cells with this siRNA resulted in a significant and reproducible decrease in Stat3 expression. The degree of knockdown ranged from 80 to $95 \%$ as determined by the levels of mRNA using real-time quantitative RT-PCR (Fig. 2A), and from 75 to $80 \%$ as determined by Western blot analysis (Fig. 2B). Transfection with siRNA specific for the GFP sequence used as a control did not reduce Stat3 expression. Interestingly, the diminished Stat 3 expression was followed by a decrease of the number of cells in the culture maintained under growth conditions in comparison to the controls (Fig. 2C). 


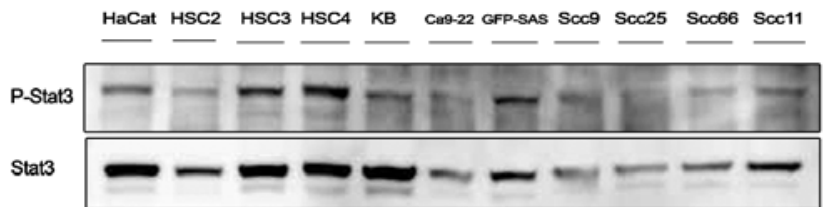

Figure 1. Phosphorylation of Stat3 in human OSCC cells. Protein samples were loaded onto a $10 \%$ SDS-polyacrylamide gel. Stat 3 expression and activation were examined by Western blot analysis.

Knockdown of Stat 3 expression by 10 designed synthetic Stat3-siRNAs. Ten double-stranded siRNAs specific for Stat3 were synthesized and tested for their ability to knock down Stat 3 expression in human OSCC cells. The range of reduction of Stat3 expression in GFP-SAS cells varied from 21 to $67 \%$ for $10 \mathrm{nM}$ siRNAs, and from 13 to $73 \%$ for $1 \mathrm{nM}$ siRNAs, as assessed by the levels of mRNAs in real-time quantitative RT-PCR (Fig. 3A). A successive decrease in protein synthesis was observed by Western blot analysis $72 \mathrm{~h}$ after transfection (Fig. 3B). Three out of the 10 screened siRNAs reduced Stat3 expression to lower levels compared with the GFP-siRNA control.

Interferon- $\gamma$ response to transfection of synthetic siRNAs. In order to examine the activation of the interferon- $\gamma$ (IFN- $\gamma$ ) pathway in response to the 10 designed siRNAs, mRNA levels of the following four interferon response genes were subjected to analysis: OAS1, OSA2, MX1 and ISGF3 $\gamma$. Increased activation of the above-mentioned genes was observed in cases of siRNA no. 9 and 10 at the working concentration of $10 \mathrm{nM}$. Transfection performed at a concentration of $1 \mathrm{nM}$ did not cause a significant elevation of any of the four mRNAs (Fig. 3C).

Effect of Stat3 knockdown on the growth of human OSCC cells. The effect of Stat 3 reduction on the proliferation of GFP-SAS, HSC-4, HSC-3 and KB cells was examined. For this experiment, the most effective Stat3-siRNAs (no. 2, 5 and 10) were applied at a working concentration of $1 \mathrm{nM}$. For the negative control GFP- and Stat3-siRNAs no. 1 and 7 were used. The total cell number in the culture was markedly decreased $72 \mathrm{~h}$ after transfection and varied depending on the siRNA sequence and the cell line. The reduction of the cell number range was $59-89 \%$ for no. $2,61-91 \%$ for no. 5 , 74-96\% for no. 10, 0-4\% for no. 1 and $1-37 \%$ for no. 7 (Fig. $4 \mathrm{~A})$. Consistent with these observations, fewer cells were observed under the microscope (Fig. 4B).

Effect of Stat3 knockdown on the expression of downstream genes. In order to investigate the functional influence of Stat3-siRNAs, the expression levels of the two genes regulated by Stat 3 were examined. The reduction in Stat 3 expression was followed by a decrease in the levels of CCND1 and VEGF. The reduction varied depending on the siRNA sequence and the cell line. For CCND1, the reductions observed were $41-62 \%$ for no. 2, 41-67\% for no. $5,52-72 \%$ for no. $10,0-8 \%$ for no. 1 and $4-25 \%$ for no. 7 , while for VEGF, the reductions were $13-68 \%$ for no. 2, 23-59\% for

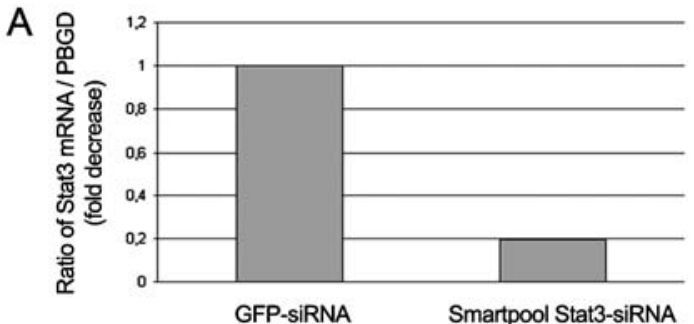

B

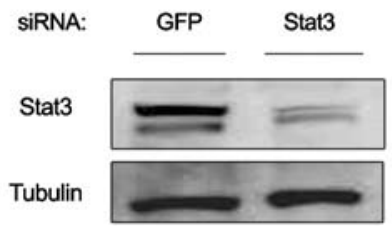

C

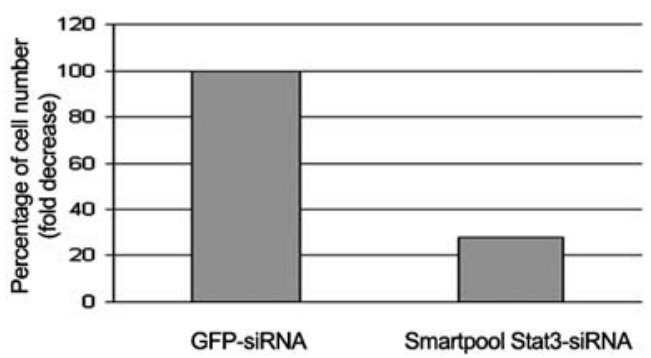

Figure 2. Effects of Smartpool Stat3-siRNA on GFP-SAS cells. (A) Decrease in Stat3 mRNA levels mediated by $10 \mathrm{nM}$ Stat3-siRNA treatment $72 \mathrm{~h}$ after the onset of the experiment, detected by real-time quantitative RT-PCR. Stat 3 mRNA levels were normalized by PBGD expression. (B) Decrease in Stat 3 expression observed by Western blot analysis. (C) Decrease in cell numbers in cultures. The values were normalized to $100 \%$.

no. $5,35-64 \%$ for no. $10,0-28 \%$ for no. 1 and $0-47 \%$ for no. 7 (Fig. 5). In contrast, the expression of MMP-10 was not significantly affected by any of the examined siRNAs.

\section{Discussion}

Stat3, a signal transducer and activator of transcription, functions as a downstream effector of cytokine and growth factor receptors $(1,18)$. It has been demonstrated that the $\mathrm{TGF} \alpha / E G F R-m e d i a t e d$ growth of transformed epithelial cells is dependent on the activation of Stat3, and that interrupting Stat 3 signalling abrogates the TGF $\alpha$-induced growth of these cells (18). Targeting constitutively active Stat 3 has repeatedly been demonstrated to inhibit tumour cell growth in vitro and in vivo $(4,11,12,14-16,18,25,26)$. Moreover, although mice lacking Stat3 die before birth (27), studies on astrocytes have revealed that the inhibition of Stat 3 signalling does not kill normal cells (15). Therefore, targeting Stat 3 provides a powerful method for therapeutic intervention in human cancer.

In our study, the targeted disruption of Stat 3 was achieved by the RNAi method using synthetic siRNA in OSCC cells, which are characterized by a high constitutive phosphorylation of Stat3. Knockdown of Stat3 expression was obtained with the Smartpool Stat3-siRNA. However, since this product is a mixture of four siRNAs, the most effective sequence 
A
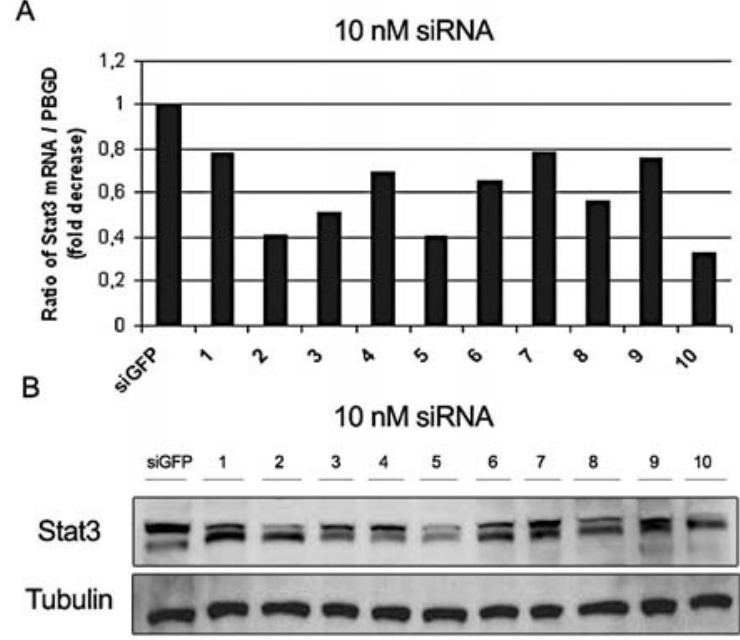

C
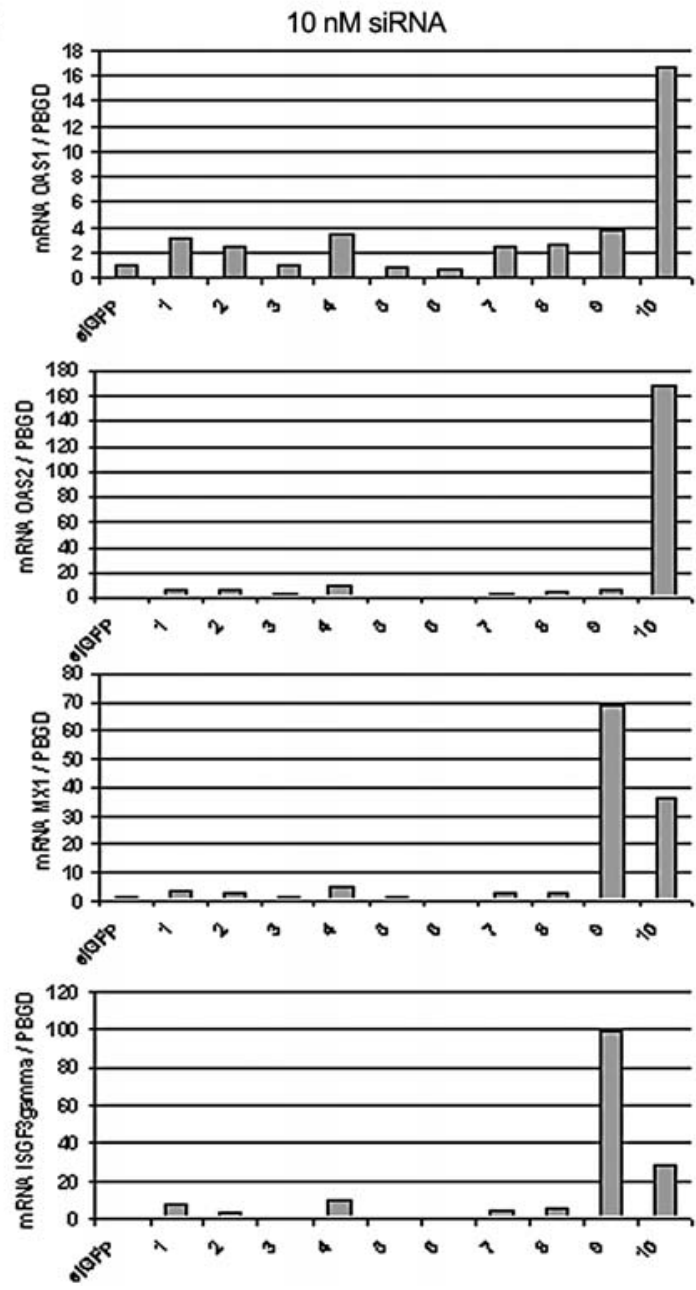
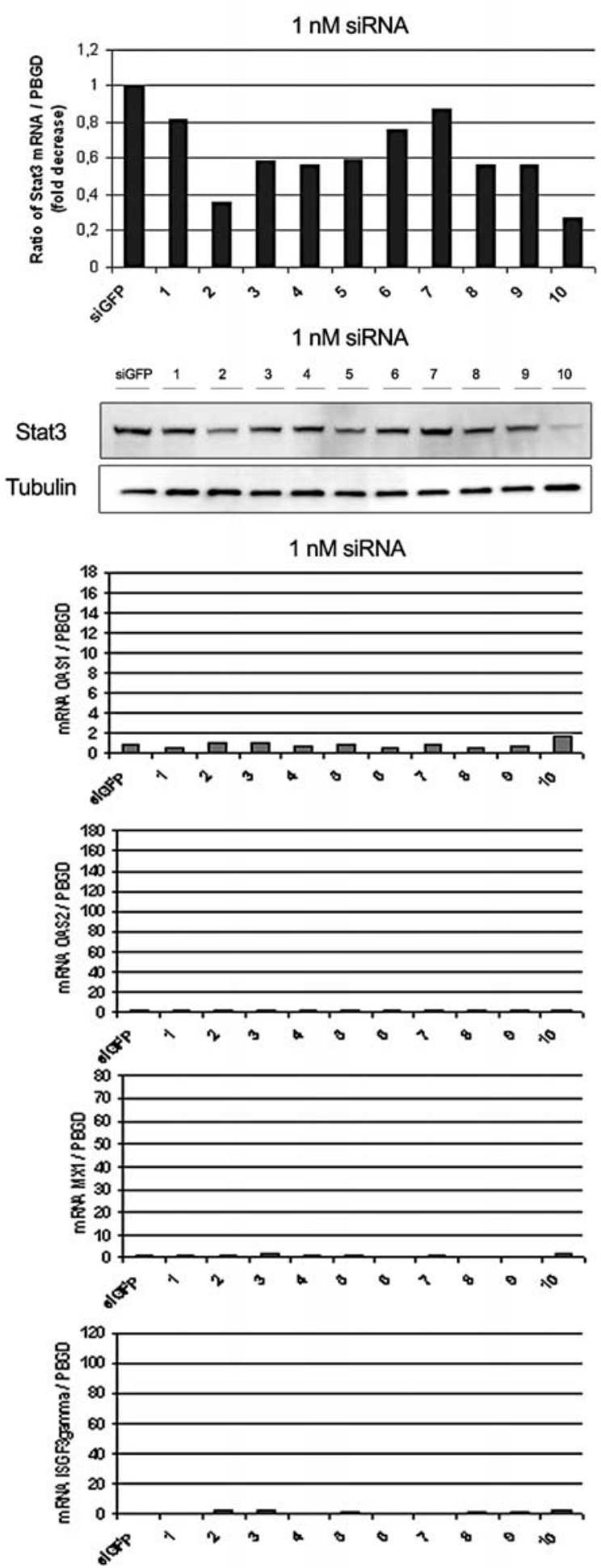

Figure 3. Knockdown of Stat3 expression by designed Stat3-siRNAs. (A) Stat3 mRNA detection after treatment of GFP-SAS cells with 1 and $10 \mathrm{nM}$ of siRNAs. (B) Western blot detection of Stat3 expression. (C) IFN response to treatment with 10 designed siRNAs. Relative mRNA levels were normalized by PBGD expression and the values were adjusted to $100 \%$.

remains unknown, and off-target effects were not considered. Therefore, we designed 10 different siRNAs corresponding to the Stat3 gene. The sequences were selected on the basis of studies of RNAi in mammalian cells (23). Interestingly, not all designed siRNAs efficiently decreased Stat3 mRNA levels. Our screening identified only three candidates as efficient Stat3-siRNAs. It should be noted that the disruption of Stat3 signalling was obtained at a markedly low working concentration of these siRNAs (1 nM) and, consistent with other studies, was found to be time-dependent with the maximum effect being achieved at $72 \mathrm{~h}$ of siRNA treatment (15). The depletion of endogenous Stat 3 by RNAi influenced cancer cell growth due to the lower cell numbers in the cultures. We failed to observe any significant increase in apoptosis under Stat3-siRNA treatment (data not shown). Stat 3 knockdown decreased the levels of the mRNAs of genes 

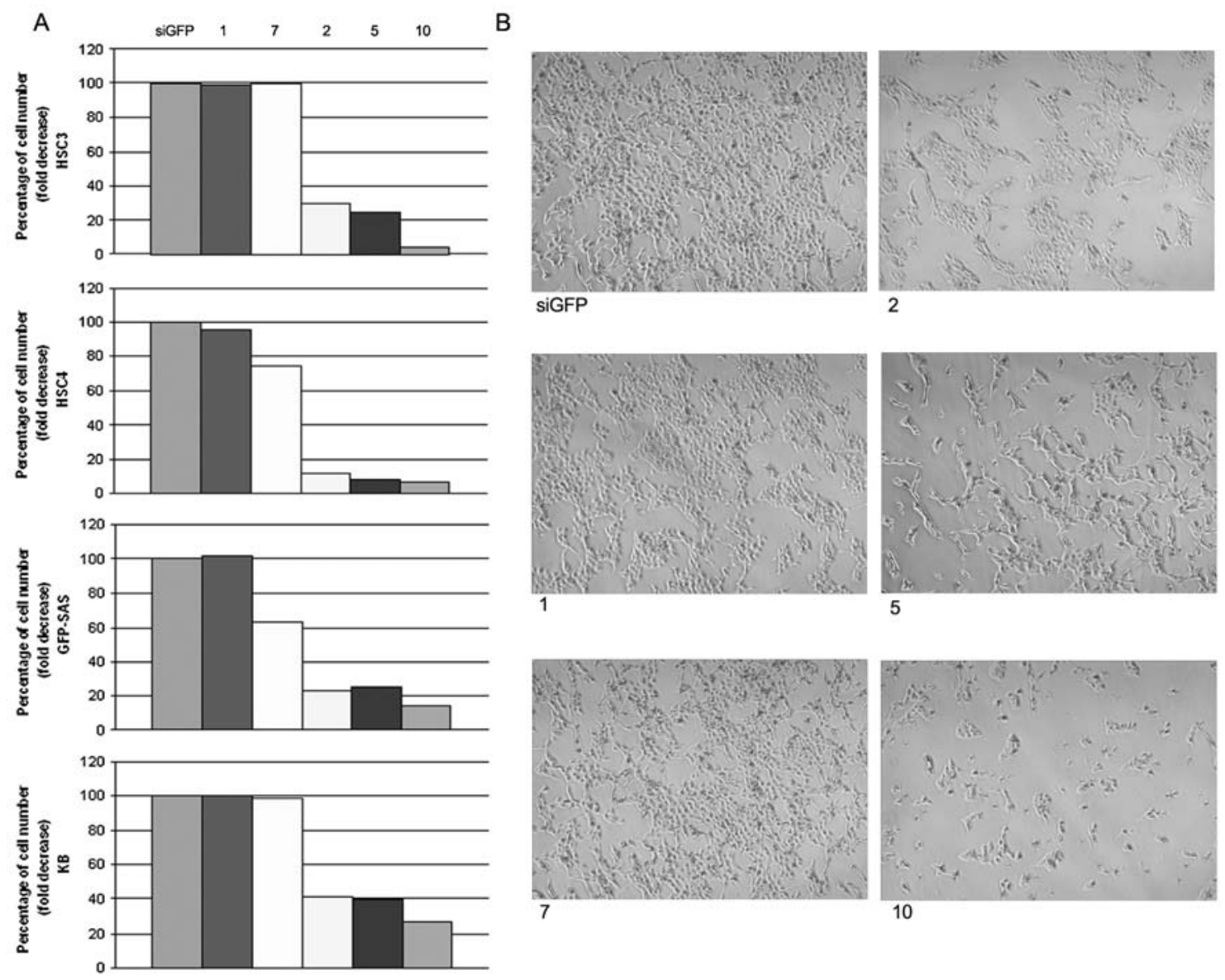

Figure 4. Growth inhibition of human OSCC cells mediated by effective Stat3-siRNAs. (A) A lower number of cells was detected in the cultures of HSC-3, HSC-4, GFP-SAS and KB cells when treated with Stat3-siRNAs no. 2, 5 or 10. GFP- and Stat3-siRNAs no. 1 and 7 were used as controls. The values were adjusted to $100 \%$. (B) Microscopic view of HSC-3 cell cultures under the relevant Stat3-siRNA treatment. Magnification, $\mathrm{x} 40$.

HSC3
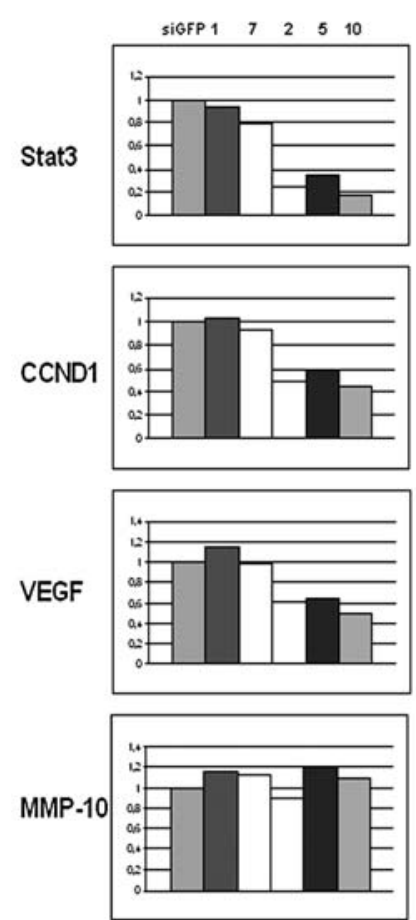

HSC4
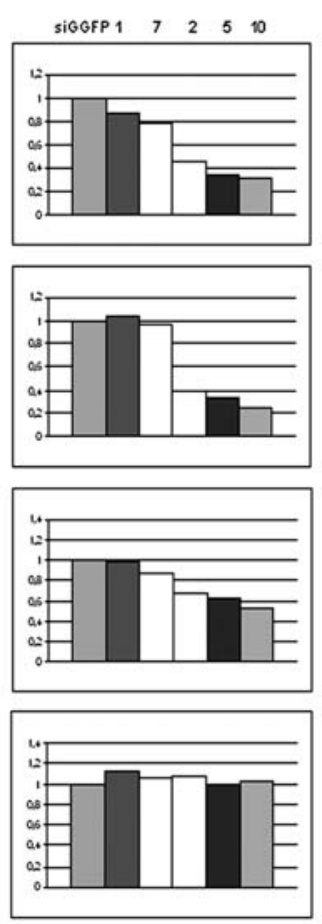

GFP-SAS
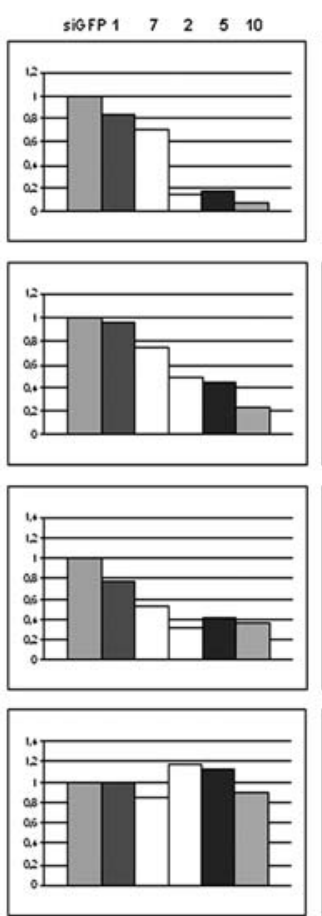

KB
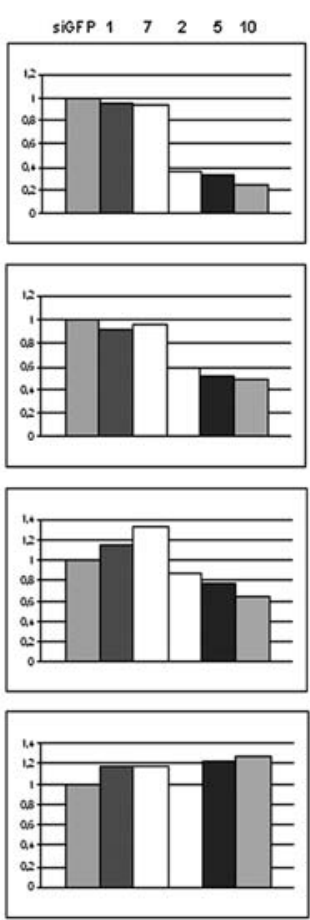

Figure 5. Suppression of CCND1 and VEGF expression by effective Stat3-siRNAs. CCND1 and VEGF mRNA levels were evaluated by real-time quantitative RT-PCR analysis. Relative mRNA levels were normalized by PBGD expression. Stat3-siRNAs no. 1 and 7 were used as controls and the values were adjusted to 1.0 . 
regulated by the binding of Stat 3 dimers to the relevant DNA-response elements.

In addition to the gene-specific silencing, siRNA can induce non-specific effects, many of which are based on the stress reaction pathways mediating cellular antiviral responses (28-30), the levels of which depend on the concentration of siRNA and the cell line (31). Stat3 itself is connected to INF- $\gamma$ signalling. It has been shown that Stat 3 activation can inhibit the expression of cytokines and chemokines induced by INF- $\gamma$ (32). Treatment of prostate cancer cells with INF- $\gamma$ has been demonstrated to be associated with the persistent dephosphorylation of constitutively tyrosine-phosphorylated Stat3 (33). Our data clearly demonstrated that low concentrations of Stat3-siRNA did not cause the interferon response. However, at higher concentrations, sequence-specific reactions may occur in a sequence-specific manner.

In this study, we demonstrated the importance of Stat3 signalling inhibition in abrogating human OSCC growth. We also identified three Stat3-siRNA sequences and propose these to be effective tools, which may be applied separately or in combination at markedly low working concentrations, to increase the number of approaches to cancer therapy.

\section{Acknowledgements}

This work was supported, in part, by a Grant-in-Aid for Scientific Research from the Ministry of Education, Science, Sports and Culture of Japan.

\section{References}

1. Buettner R, Mora LB and Jove R: Activated STAT signalling in human tumors provides novel molecular targets for therapeutic intervention. Clin Cancer Res 8: 945-954, 2002.

2. Hirano T, Ishihara K and Hibi M: Roles of STAT3 in mediating the cell growth, differentiation and survival signals relayed through the IL-6 family of cytokine receptors. Oncogene 19: 2548-2556, 2000.

3. Bromberg JF, Wrzeszczynska MH, Devgan G, et al: Stat3 as an oncogene. Cell 98: 295-303, 1999.

4. Catlett-Falcone R, Landowski TH, Oshiro MM, et al: Constitutive activation of Stat3 signaling confers resistance to apoptosis in human U266 myeloma cells. Immunity 10: 105-115, 1999.

5. Benkeli M, Baer MR, Baumann H and Wetzler M: Signal transducer and activator of transcription proteins in leukemias. Blood 101: 2940-2954, 2003.

6. Dhir R, Ni Z, Lou W, DeMiguel F, Grandis JR and Gao AC: Stat3 activation in prostatic carcinomas. Prostate 51: 241-246, 2002.

7. Masuda M, Suzui M, Yasumatsu R, et al: Constitutive activation of signal transducers and activators of transcription 3 correlates with cyclin D1 overexpression and may provide a novel prognostic marker in head and neck squamous cell carcinoma. Cancer Res 62: 3351-3355, 2002.

8. Wei D, Le X, Zheng L, et al: Stat3 activation regulates the expression of vascular endothelial growth factor and human pancreatic cancer angiogenesis and metastasis. Oncogene 22: 319-329, 2003.

9. Lai R, Rassidakis GZ, Medeiros LJ, Leventaki V, Keating M and McDonnell TJ: Expression of Stat3 and its phosphorylated forms in mantle cell lymphoma cell lines and tumours. J Pathol 199: 84-89, 2003.

10. Klosek SK, Nakashiro K, Hara S, Li C, Shintani S and Hamakawa H: Constitutive activation of Stat 3 correlates with increased expression of the c-Met/HGF receptor in oral squamous cell carcinoma. Oncol Rep 12: 293-296, 2004.

11. Kijima T, Niwa H, Steinman RA, et al: STAT3 activation abrogates growth factor dependence and contributes to head and neck squamous cell carcinoma tumor growth in vivo. Cell Growth Differ 13: 355-362, 2002.
12. Gao L, Zhang L, Hu J, et al: Down-regulation of signal transducer and activator of transcription 3 expression using vector-based small interfering RNAs suppresses growth of human prostate tumor in vivo. Clin Cancer Res 11: 6333-6341, 2005.

13. Corvinus FM, Orth C, Moriggl R, et al: Persistent STAT3 activation in colon cancer is associated with enhanced cell proliferation and tumor growth. Neoplasia 7: 545-555, 2005.

14. Rahaman SO, Harbor PC, Chernova O, Barnett GH, Vogelbaum MA and Haque SJ: Inhibition of constitutively active Stat 3 suppresses proliferation and induces apoptosis in glioblastoma multiforme cells. Oncogene 21: 8404-8413, 2002.

15. Konnikova L, Kotecki M, Kruger MM and Cochran BH: Knockdown of STAT3 expression by RNAi induces apoptosis in astrocytoma cells. BMC Cancer 3: 23, 2003.

16. Grandis JR, Drenning SD, Zeng Q, et al: Constitutive activation of Stat3 signaling abrogates apoptosis in squamous cell carcinogenesis in vivo. Proc Natl Acad Sci USA 97: 4227-4232, 2000.

17. Hsieh FC, Cheng G and Lin J: Evaluation of potential Stat3regulated genes in human breast cancer. Biochem Biophys Res Commun 335: 292-299, 2005.

18. Grandis JR, Drenning SD, Chakraborty A, et al: Requirement of Stat 3 but not Stat 1 activation for epidermal growth factor receptormediated cell growth in vitro. J Clin Invest 102: 1385-1392, 1998.

19. Li L and Shaw PE: Autocrine-mediated activation of STAT3 correlates with cell proliferation in breast carcinoma lines. J Biol Chem 277: 17397-17405, 2002.

20. Kraker AJ, Hartl BG, Amar AM, Barvian MR, Showalter HD and Moore CW: Biochemical and cellular effects of c-Src kinase-selective pyrido[2,3-d]pyrimidine tyrosine kinase inhibitors. Biochem Pharmacol 60: 885-898, 2000.

21. Turkson J, Ryan D, Kim JS, et al: Phosphotyrosyl peptides block Stat3-mediated DNA binding activity, gene regulation, and cell transformation. J Biol Chem 276: 45443-45455, 2001.

22. Leong PL, Andrews GA, Johnson DE, et al: Targeted inhibition of Stat3 with a decoy oligonucleotide abrogates head and neck cancer cell growth. Proc Natl Acad Sci USA 100: 4138-4143, 2003.

23. Elbashir SM, Harborth J, Weber K and Tuschl T: Analysis of gene function in somatic mammalian cells using small interfering RNAs. Methods 26: 199-213, 2002.

24. Ling X and Arlinghaus RB: Knockdown of STAT3 expression by RNA interference inhibits the induction of breast tumors in immunocompetent mice. Cancer Res 65: 2532-2536, 2005.

25. Garcia R, Bowman TL, Niu G, et al: Constitutive activation of Stat 3 by the Src and JAK tyrosine kinases participates in growth regulation of human breast carcinoma cells. Oncogene 20: 2499-2513, 2001.

26. Epling-Burnette PK, Liu JH, Catlett-Falcone R, et al: Inhibition of STAT3 signaling leads to apoptosis of leukemic large granular lymphocytes and decreased Mcl-1 expression. J Clin Invest 107: 351-362, 2001.

27. Takeda K, Noguchi K, Shi W, et al: Targeted disruption of the mouse Stat 3 gene leads to early embryonic lethality. Proc Natl Acad Sci USA 94: 3801-3804, 1997.

28. Scacheri PC, Rozenblatt-Rosen O, Caplen NJ, et al: Short interfering RNAs can induce unexpected and divergent changes in the levels of untargeted proteins in mammalian cells. Proc Natl Acad Sci USA 101: 1892-1897, 2004.

29. Bridge AJ, Pebernard S, Ducraux A, Nicoulaz AL and Iggo R: Induction of an interferon response by RNAi vectors in mammalian cells. Nat Genet 34: 263-264, 2003.

30. Pebernard S and Iggo RD: Determinants of interferon-stimulated gene induction by RNAi vectors. Differentiation 72: 103-111, 2004.

31. Persengiev SP, Zhu X and Green MR: Non-specific, concentrationdependent stimulation and repression of mammalian gene expression by small interfering RNAs (siRNAs). RNA 10: 12-18, 2004.

32. Wang T, Niu G, Kortylewski M, et al: Regulation of the innate and adaptive immune responses by Stat- 3 signaling in tumor cells. Nat Med 10: 48-54, 2004.

33. Fang P, Hwa V and Rosenfeld RG: Interferon-gamma-induced dephosphorylation of STAT3 and apoptosis are dependent on the mTOR pathway. Exp Cell Res 312: 1229-1239, 2006. 